\title{
Positive attitudinal shifts with the Physics by Inquiry curriculum across multiple implementations
}

\author{
Beth A. Lindsey, ${ }^{1}$ Leonardo Hsu, ${ }^{2}$ Homeyra Sadaghiani, ${ }^{3}$ Jack W. Taylor, ${ }^{4}$ and Karen Cummings ${ }^{5}$ \\ ${ }^{1}$ Physics, Penn State Greater Allegheny, McKeesport, Pennsylvania 15132, USA \\ ${ }^{2}$ Department of Postsecondary Teaching and Learning, University of Minnesota, Minneapolis, Minnesota 55455, USA \\ ${ }^{3}$ Department of Physics and Astronomy, California State Polytechnic University, Pomona, California 91791, USA \\ ${ }^{4}$ Department of Natural and Physical Sciences, Baltimore City Community College, Baltimore, Maryland 21215, USA \\ ${ }^{5}$ Physics Department, Southern Connecticut State University, New Haven, Connecticut 06515, USA
}

(Received 18 August 2011; published 30 January 2012)

\begin{abstract}
Recent publications have documented positive attitudinal shifts on the Colorado Learning Attitudes about Science Survey (CLASS) among students enrolled in courses with an explicit epistemological focus. We now report positive attitudinal shifts in classes using the Physics by Inquiry (PbI) curriculum, which has only an implicit focus on student epistemologies and nature of science issues. These positive shifts have occurred in several different implementations of the curriculum, across multiple institutions and multiple semesters. In many classes, students experienced significant attitudinal shifts in the problemsolving categories of the CLASS, despite the conceptual focus of most $P b I$ courses.
\end{abstract}

DOI: 10.1103/PhysRevSTPER.8.010102

PACS numbers: 01.40.Fk, 01.40.G-, 01.40.Di

\section{INTRODUCTION}

Over the past ten years, physics education researchers have begun to investigate much more intensively students' attitudes and beliefs about physics and the learning of physics, as well as the effects those attitudes and beliefs may have on students' learning of physics [1-4]. By attitudes, we do not mean merely whether students have a personal interest in physics, but also aspects such as their view of the coherence of physics knowledge, the relevance of the physics they learn in class to the real world, and the connection between mathematical equations and physics concepts. Studies have shown that students' epistemologies of physics affect their framing of the activities and assignments in a physics course and thus these epistemologies might also be expected to have an impact on students' perception of the goals of a physics course, and of learning science in general $[5,6]$.

A number of surveys have been developed and used to measure students' attitudes in physics, including the Maryland Physics Expectations (MPEX) survey [1], the Epistemological Beliefs Assessment for Physical Science (EBAPS) [2], and the Colorado Learning Attitudes about Science Survey (CLASS) [3]. Unfortunately, it has been well established that in the introductory physics courses taken by a majority of students (typically an algebra-based or calculus-based course or two for students whose majors require them to take physics), students' attitudes and beliefs about physics and the learning of physics remain about the same or become less expertlike over the course

Published by the American Physical Society under the terms of the Creative Commons Attribution 3.0 License. Further distribution of this work must maintain attribution to the author(s) and the published article's title, journal citation, and DOI. of the semester in which they take physics; i.e., their attitudes and beliefs at the end of the course are less similar to those of experts than at the beginning [3]. This is true both of courses taught with a very traditional pedagogy and courses taught using interactive engagement techniques that do not simultaneously attend to student beliefs $[3,4]$.

There have been a few exceptions reported in the literature. Otero and Gray [7] reported significant gains in prepost CLASS scores across multiple university classes using the Physics for Everyday Thinking (PET) or Physical Science for Everyday Thinking (PSET) curricula [8]. The PET and PSET curricula are guided-inquiry-based curricula designed for preservice elementary teachers that address questions about the nature of science and ask students explicitly to reflect on their own experiences learning science [9]. Brewe, Kramer, and O'Brien conducted a pilot study of student attitudes using the CLASS survey in a two-semester introductory physics sequence at Florida International University using Modeling Instruction [10]. Modeling instruction replicates the activities of practicing scientists, and this was made reasonably explicit to students throughout the course. Redish and Hammer wrote about the redesign of a large-scale introductory physics course for biological science majors in which discussions of the epistemology of physics were made an explicit and integral part of the course [11]. Assessing student attitudes in this class using a revised version of the MPEX (MPEX-II) showed significant gains along multiple dimensions. Finally, Abd-El-Khalick found that using activities explicitly designed to target nature of science ideas in a science content course for prospective elementary teachers could lead to vast improvements in students' responses on a questionnaire regarding their views on the nature of science (VNOS) [12]. These instances provide four examples in which explicit attention to epistemology and the nature 
of science can result in significant positive shifts in student attitudes.

However, what might be the effect of courses that only implicitly address students' epistemologies about science? This question is an important one as many of the physics curricula that are designed for elementary teachers are guided-inquiry based and use the learning cycle model, but do not have as explicit an emphasis on the nature of science as Modeling, PSET, or PET. Given the limited time in a semester, any explicit discussion of these issues reduces the time available for science content. However, because elementary teachers reach children at the earliest stages of their science learning, there are numerous reasons why it is important for such teachers to have attitudes and beliefs about science that accurately reflect the practice of science. Thus far, there are some indications that an implicit focus may not be sufficient. Hrepic et al. [13] reported only a very small positive shift or a negative shift in CLASS scores for two relatively small classes $(N=14$ and $N=20$ ) using the Operation Primary Physical Science curriculum, designed specifically for preservice elementary teachers. Similarly, Rebello and Mamolo found no significant shifts in overall EBAPS or VNOS scores for another physics education research (PER)-based curriculum aimed at future elementary teachers [14].

In this paper, we describe a study to investigate students' attitudinal shifts in courses taught using Physics by Inquiry $(P b I)$ [15]. Like many other curricula for preservice elementary teachers, $P b I$ is a guided-inquiry-based class using learning cycles. Similar to Modeling Instruction, the activities performed by students mirror the process by which practicing scientists create new knowledge. However, the nature of physics and the learning of physics are never addressed explicitly by the curriculum, only implicitly through the classroom activities. As we shall see, the shifts in students' responses to the CLASS are positive, statistically significant, and roughly as large as the shifts seen in classes using the PET and PSET curricula for the majority of $P b I$ classes. In addition, we see large gains along certain dimensions defined by the CLASS, most notably those related to problem solving. These gains are unexpected given the lack of emphasis of $P b I$ on problem solving in the traditional sense. However, as we shall also see, these shifts can vary substantially from one semester to another and the causes of the differences are not yet clear.

\section{IMPLEMENTATIONS OF PHYSICS BY INQUIRY}

Physics by Inquiry was developed by the Physics Education Group at the University of Washington (UW) and is designed to help preservice and in-service K-12 teachers learn physics content. It has also been used in courses for nonscience majors. The curriculum is divided into a number of modules, each of which addresses a different topic, such as kinematics, light and color, astronomy by sight, electric circuits, magnets, etc. Students work in small groups to perform experiments using simple materials and are guided by questions in the text to generate models of how things work based on the experimental evidence they have gathered. Students then perform further experiments to test, develop, and modify their models. Although these class activities reflect well the process by which scientific knowledge is generated, there is no special effort in the curriculum to make the students aware of this. During their work, students keep a laboratory notebook in which they record their observations and working theories. Exams are open book and open notes, but require students to be able to apply the ideas they have learned to situations that they have never encountered. Rote memorization or looking for answers in the book or one's notes are thus typically not helpful. In a traditional implementation, such as the one at the University of Washington, the class sizes are small (roughly 20 students), the student-to-staff ratio is kept low (about 7:1 or 10:1), the students work in groups of two or three, and the course staff are either physics faculty or well-trained graduate students who are knowledgeable about physics and physics education. None of the course time is devoted to lectures, and very little is devoted to large-group discussions. Instead, virtually all of the interactions between faculty and students take place during small-group "checkouts," in which an instructor probes the understanding of a group of students with a series of targeted questions. Throughout the literature, there are numerous reports that show that the $P b I$ curriculum is very effective at helping students learn physics concepts in a flexibly applicable way [16,17], even in cases where institutional constraints mandate a deviation from the ideal implementation [18].

Our data come from Physics by Inquiry courses taught in five different environments. Data collected from each implementation are summarized in Table I. Each implementation departs from the traditional model in one or more significant ways. Implementation $A$ was a course taught at the University of Minnesota (UM), though not in the physics department. In early implementations, the students in the class were roughly $25 \%$ preservice elementary teachers and $75 \%$ other nonscience majors seeking to fulfill a physical science requirement. Over the years, the percentage of preservice elementary teachers has increased to almost $75 \%$. Typically, about $75 \%$ of the students in the course are female. This implementation adhered closely to the $P b I$ curriculum, using material from the electric circuits, properties of matter, and light and color sections, although the amount of material from each section occasionally changed. The main difference between this course and a traditional implementation was in the larger class size of up to 45 students per section, the larger student-tostaff ratio (ranging from 12:1 up to 15:1), the slightly larger student groups (occasionally as large as four students), and the fact that the course staff consisted of one faculty member (L.H.) and a number of undergraduate teaching 
TABLE I. Implementations of Physics by Inquiry. The first five lines of the table provide pertinent details for the implementations involved in this study; the final line describes the "canonical" implementation recommended by the University of Washington Physics Education Group. We do not include semesters or total enrollment for the canonical implementation, as that was not a part of this study.

\begin{tabular}{|c|c|c|c|c|c|c|}
\hline Implementation & Institution & Semesters & $\begin{array}{c}\text { Typical } \\
\text { student-to- } \\
\text { staff ratio }\end{array}$ & Instructional staff & Checkouts & $\begin{array}{c}\text { Total } \\
\text { enrollment } \\
\text { (surveys } \\
\text { counted) }\end{array}$ \\
\hline$A$ & UM & Fall 2004-Fall 2009 & $12: 1-15: 1$ & Faculty, undergraduate TAs & Groups of $3-4$ & $535(409)$ \\
\hline$B$ & GU & Spring 2009-Spring 2010 & $17: 1$ & Faculty, graduate TA & $\begin{array}{l}\text { Whole class } \\
\text { discussion }\end{array}$ & $71(56)$ \\
\hline$C$ & $\mathrm{CPP}$ & Fall 2007 & $16: 1$ & Faculty & Groups of 2-3 & $16(16)$ \\
\hline$D$ & SCSU & Fall 2005-Spring 2011 & 16.5:1-20:1 & Faculty, undergraduate TAs & Groups of $2-3$ & $127(96)$ \\
\hline$E$ & $\mathrm{BCCC}$ & Spring 2005-Fall 2006 & $\leq 10: 1$ & Faculty, undergraduate TAs & Groups of $2-3$ & $40(38)$ \\
\hline Canonical & UW & & $\leq 10: 1$ & Faculty, PER graduate TAs & Groups of 2-3 & \\
\hline
\end{tabular}

assistants (TAs). The TAs were students who had previously taken the course, performed well on the tests, and worked well with their lab partners. During the semester, the instructor and TAs met each week for 2 hours to review course content and to discuss student difficulties and methods for helping students learn the material effectively.

Implementation $B$ was a course taught at Georgetown University (GU) in the physics department. The students in the class were entirely nonscience majors taking the course to fulfill their core science requirement. The $P b I$ modules covered varied from year to year: In both years, students completed material from the electric circuits module. In 2009 , this was paired with material from astronomy by sight, while in 2010, students instead completed the first 5 sections of the kinematics module. The course enrollments were approximately 35 students and the instructional staff consisted of a faculty member (B. A. L.) and a graduate student, resulting in a student-to-staff ratio of at least 17:1. The graduate students assigned as TAs to the course were assigned arbitrarily: Neither had ever taken any similar course, but worked through the curriculum on their own, and met regularly with the instructor during the course of the semester. A key difference between this implementation and a traditional implementation of $P b I$ at the University of Washington was the lack of one-on-one checkouts between a member of the instructional staff and a group of students. Although instructors had many one-on-one interactions with students during each class period, these were often limited to brief troubleshooting exchanges, not in-depth conversations to probe student understanding. Instead, the faculty member conducted a full-class checkout at the end of each period in which she asked students to summarize key points of the day's experiments for their classmates and raised discussions of common student difficulties with the class as a whole.

Implementation $C$ was a course offered by the physics department in the elementary (K-8) science teacher education program at California Polytechnic University, Pomona (CPP). This one-quarter course is one of three science courses required for students to fulfill their science requirement for the CPP multiple subject teacher credential program. The majority of students taking the course are liberal arts majors (90\% female) with little or no math or science background. The topics of the course were chosen to address the California Science Standards for K-8 students and included properties of matter, heat and temperature, energy, and light and color. In 2007, the instructor (H.S.) used the Physics by Inquiry textbook and followed the University of Washington approach including using checkouts with individual groups to probe students' understanding. The main deviation from the course as implemented at UW was again the instructor-to-student ratio. The course instructor was the only staff member interacting with the 16 students during class.

Implementation $D$ was a one-semester course taught at Southern Connecticut State University (SCSU). Although listed as being for preservice teachers, the students in the class included a mix of preservice teachers and students taking the course to satisfy a general education requirement. Because of the need for the course to address state standards for elementary school science as well as the needs of regional schools, the course curriculum was not limited to Physics by Inquiry, but also included substantial time (about $40 \%$ of the class) working with "Science and Technology for Children" (STC) kits [19], which are widely used in regional schools. The course covered three topics, each of which was addressed by both $P b I$ and the STC kits: electric circuits (with an emphasis on a current model of electricity), magnets and motors (the electromagnets unit in $P b I$ ), and force and motion (the kinematics unit in $P b I$ ). Students worked in groups of approximately 3 , and checkouts similar to those at the University of Washington were conducted. The typical student-to-staff ratio in the course during the time period reported here was about 20:1. In one of the reported semesters the courses was taught with an enrollment of 33 students, the instructor, and one undergraduate teaching assistant (ratio 16.5:1). In other terms, the enrollment averaged around 20 with only the instructor present (ratio 20:1) 
Implementation $E$ was a one-semester physical science course primarily for nonscience majors and some education majors taught at Baltimore City Community College (BCCC). BCCC is an urban community college serving a predominately African-American population. The class concentrated on portions of the properties of matter, electric circuits, heat and temperature, and light and color modules. Students worked in small groups during class, which was primarily a hands-on laboratory course, but with occasional whole-class discussions led by the instructor. TAs were mostly education majors with a good understanding of the content, who prepared by attending a short meeting with the instructor before every class. The TAs assisted student groups when help was needed, helped move students along if there were "stuck," and performed checkouts to verify the students' understanding. The student-to-staff ratio was similar to that in a traditional (UW) implementation.

\section{METHODS}

We measured students' attitudes and beliefs about physics and the learning of physics, using the CLASS, a 42-item survey developed at the University of Colorado [3]. Each item consists of a statement to which students respond on a 5-point Likert scale ranging from strongly disagree to strongly agree. Of the 42 items, 36 have responses to which experts, such as physics faculty, agree. An overall score can be calculated for each student as the percentage of answers that match the expert response. Furthermore, eight nonmutually exclusive groups of questions have been found to which students' responses to the questions in a group are highly correlated. These groups define eight categories that have been given names such as personal interest, real world connection, problem solvingconfidence, and conceptual understanding, based on the nature of the statements in each group. Students' scores in each of these categories can also be computed.

We chose the CLASS because (1) many data have been published on CLASS results for different types of physics courses, (2) the survey items are worded in a such a way as to be interpretable by students who have not taken physics, and (3) CLASS results are known to depend on features of the instruction (producing significant positive pre-post shifts in cases where explicit attention is paid to students' epistemologies of physics).

The administration of the surveys was similar across all of the $P b I$ implementations. Students filled out surveys near the beginning (pre) and end (post) of the semester. In all implementations except $B$, the surveys were completed in class. In Implementation $B$, they were completed on the web. No incentives were offered to students for completing the surveys, and the instructor of each class emphasized that students' responses on the survey would in no way affect their grades in the course. In order for a student's results to be included in the data analysis (1) the student must have completed both the pre and post surveys and both surveys must have fulfilled criteria (2) and (3), (2) the student must have correctly responded to item no. 31 , which is worded to identify students who are not reading or do not understand the surveys, (3) the student must have answered at least 38 of the 42 items. If a student gave the same response for more than 25 of the survey items (a possible sign that the student is not taking the survey seriously), their responses were visually inspected to determine whether they appeared to begin by selecting answers seriously and then shifted to selecting the same answer for each question. Pre and post scores for each class section were computed by averaging student scores.

In addition to the CLASS, students in several of the $\mathrm{PbI}$ classes were asked to respond to some written prompts to help clarify some of the reasons behind the shifts, particularly in the problem-solving categories.

\section{RESULTS AND DISCUSSION}

Overall pre- and postcourse scores on the CLASS at several different institutions are reported in Fig. 1. As can be seen from the data, on average, the $P b I$ curriculum produces large positive shifts. Because the distributions of CLASS scores deviated from the normal distribution, statistical significance of the gains was determined using the nonparametric Wilcoxon signed-rank test, using Bonferroni-adjusted alpha levels of 0.01 per test. However, these gains are not necessarily stable. Because of large variations in sample size, the nonparametric Kruskal-Wallis test was chosen to compare gains across institutions, revealing significant differences in overall CLASS gains between the five implementations $(p<$ $0.05)$. Even at a single institution with the same instructor, the magnitude of the gains can vary from semester to semester. Figure 2 shows the results by semester for

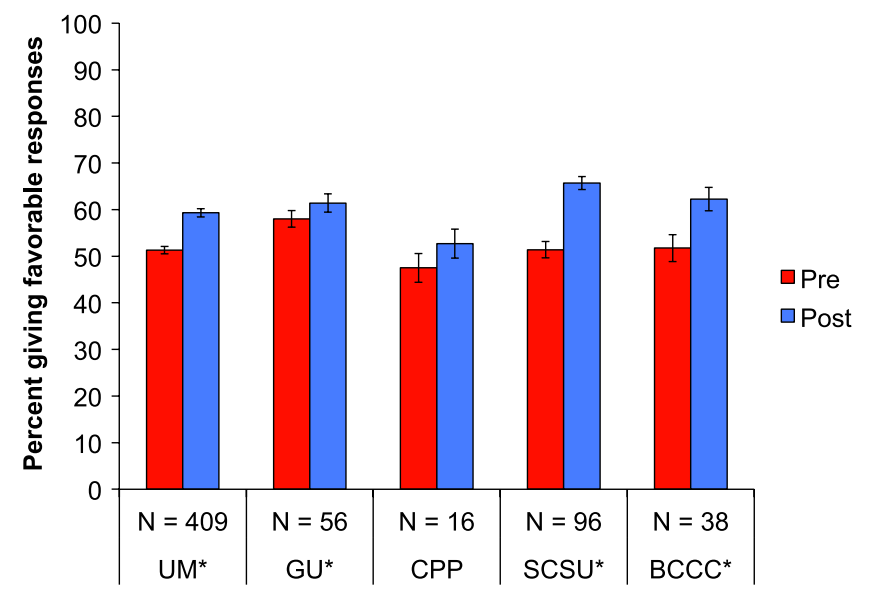

FIG. 1 (color online). Average CLASS scores at the beginning (Pre) and end (Post) of the course for all five implementations of Physics by Inquiry. Error bars are the standard error of the mean. * indicates statistical significance with $p<0.01$ on a Wilcoxon signed-rank test. 


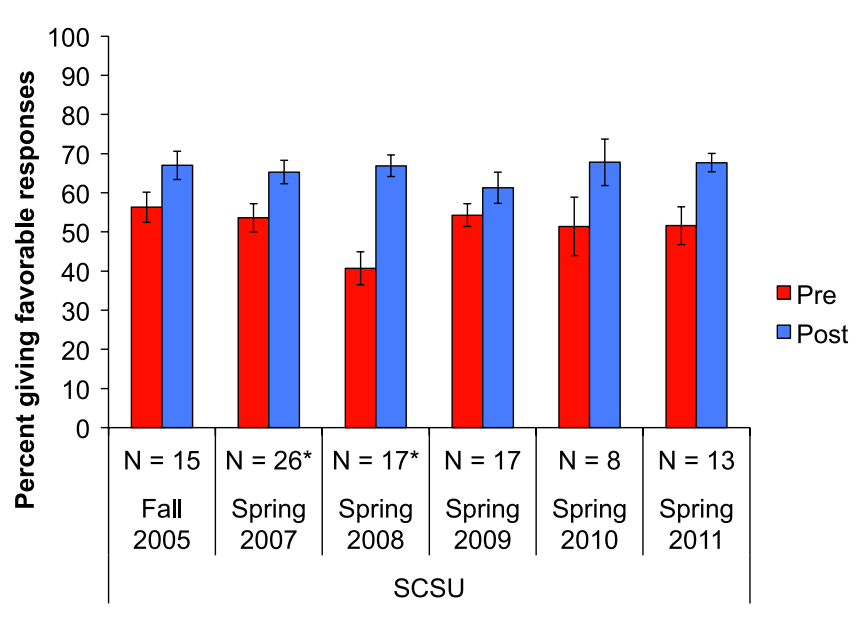

FIG. 2 (color online). CLASS scores at Southern Connecticut State University at the beginning (Pre) and end (Post) of each semester. Error bars are the standard error of the mean.* indicates statistical significance with $p<0.008$ on a Wilcoxon signed-rank test.

implementation $D$, which had the greatest fluctuations. The nonparametric Kruskal-Wallis test was used to compare these shifts by semester. This test revealed a significant difference between the shifts by semester $(p<0.05)$. Despite the variation, however, we note that the overall shifts are always positive.

The gains in overall CLASS score in $P b I$ classes are consistent with gains observed with other research-based, inquiry oriented curricula. Otero and Gray report gains in the overall favorable scores on the CLASS ranging from $+3.9 \%$ to $+16.5 \%$ using the PET and PSET curricula [7]. In this study, gains on the CLASS with the $P b I$ curriculum ranged from $+1.9 \%$ to $+25.1 \%$. In both studies, student prescores on the CLASS were similar: Otero and Gray report an average CLASS pretest score of $54 \%$ in PET and PSET classes, while the average in the present study was $51 \%$. Brewe, et al. report shifts of $+12.0 \%$ in a single semester of physics taught using the Modeling method [10]. Our data therefore suggest that $P b I$ does at least as well as other research-validated curricula at moving students toward more expertlike attitudes, despite its lack of an explicit focus on epistemology. In contrast, the developers of the CLASS report shifts in overall CLASS score in large-enrollment courses ranging from $-9.8 \%$ (in an algebra-based course for premedical students) to $+1.5 \%$ (in a calculus-based course for engineering majors). In a first-semester physics course for nonscience majors, student prescores on the CLASS were 57\%, and shifts were $+1.0 \%$ [4].

Also of interest are the gains on the CLASS broken down by category. Statistically significant gains were observed in the conceptual understanding and applied conceptual understanding categories in 4 implementations and similar gains were seen in the problem solving-general, problem solving-confidence, and problem solvingsophistication categories in 3 implementations. The only one of the eight CLASS categories in which we occasionally observed losses (in one implementation) was the real world connections category.

CLASS items in the conceptual understanding and applied conceptual understanding categories include statements such as, "A significant problem in learning physics is being able to memorize all the information I need to know," and "If I don't remember a particular equation needed to solve a problem on an exam, there is nothing I can do (legally!) to come up with it." Agreement with these statements may signify a recognition by students that all of physics is based on a small number of fundamental principles, but might also be related to the structure of the course. In all of the $P b I$ implementations include here, exams were given in an open-book and open-notes format (as they are in most $\mathrm{PbI}$ courses). This policy is part of the implicit instruction on the nature of learning physics and the epistemological beliefs we wish to foster in our students; we want to emphasize the importance of focusing on understanding the fundamental concepts and being able to apply them flexibly, rather than just memorizing formulas.

The structure of the $P b I$ course alone, however, is unlikely to account for all of the gains in the conceptual categories of the CLASS. An unexpected shift toward expertlike responses was also seen on statements such as, "Knowledge in physics consists of many disconnected topics." If anything, the modular nature of $\mathrm{PbI}$ might be expected to increase student agreement with this statement, rather than to decrease agreement as actually occurs.

The statistically significant gains across the problemsolving categories in many $\mathrm{PbI}$ implementations are also noteworthy. The statements in these categories are shown in Table II, and the gains are shown by institution in Figs. 3(a)-3(c). The gains in these categories are surprising because $P b I$ does not seem to focus on problem solving in the traditional sense that students expect-they are rarely asked to solve numerical problems in class, on homework, or on exams. Instead, they are asked to make qualitative predictions about physical phenomena. High gains in the problem-solving categories may indicate that students come to consider the tasks they are asked to do in $P b I$ as problem solving. The variations in gain by section, however, are still unaccounted for.

In several sections, students were asked to respond to written prompts based on statements from the problemsolving categories on the CLASS. These prompts were

(1) How confident are you that you can solve physics problems? Please include some explanation with your answer.

(2) What is the meaning behind physics equations? Are they for doing calculations? Do they tell us something about the world? Both? Explain. 
TABLE II. Statements in the problem-solving (PS) categories of the CLASS, by category.

\begin{tabular}{|c|c|c|c|}
\hline Statement & PS-general & PS-confidence & PS-sophistication \\
\hline $\begin{array}{l}\text { After I study a topic in physics and feel that I understand it, I have } \\
\text { difficulty solving problems on the same topic. }\end{array}$ & & & $\mathrm{X}$ \\
\hline $\begin{array}{l}\text { I do not expect physics equations to help my understanding of the ideas; } \\
\text { they are just for doing calculations. }\end{array}$ & $\mathrm{X}$ & & \\
\hline $\begin{array}{l}\text { If I get stuck on a physics problem on my first try, I usually try to figure out } \\
\text { a different way that works. }\end{array}$ & $\mathrm{X}$ & $\mathrm{X}$ & \\
\hline Nearly everyone is capable of understanding physics if they work at it. & $\mathrm{X}$ & $\mathrm{X}$ & \\
\hline $\begin{array}{l}\text { If I don't remember a particular equation needed to solve a problem on an } \\
\text { exam, there's nothing much I can do (legally!) to come up with it. }\end{array}$ & & & $X$ \\
\hline $\begin{array}{l}\text { If I want to apply a method used for solving one physics problem to } \\
\text { another problem, the problems must involve very similar situations. }\end{array}$ & & & $\mathrm{X}$ \\
\hline I enjoy solving physics problems. & $\mathrm{X}$ & & $\mathrm{X}$ \\
\hline $\begin{array}{l}\text { In physics, mathematical formulas express meaningful relationships } \\
\text { among measurable quantities. }\end{array}$ & $\mathrm{X}$ & & \\
\hline I can usually figure out a way to solve physics problems. & $\mathrm{X}$ & $\mathrm{X}$ & $\mathrm{X}$ \\
\hline $\begin{array}{l}\text { If I get stuck on a physics problem, there is no chance I'll figure it out on } \\
\text { my own. }\end{array}$ & $\mathrm{X}$ & $\mathrm{X}$ & $\mathrm{X}$ \\
\hline $\begin{array}{l}\text { When studying physics, I relate the important information to what I already } \\
\text { know rather than just memorizing it the way it is presented. }\end{array}$ & $\mathrm{X}$ & & \\
\hline
\end{tabular}

(3) If you get stuck while working on a physics problem (if you forget the equation you need, for example), what do you do or what could you do about it?

Responses to these questions reveal that students can emerge from a $P b I$ course with a more inclusive or sophisticated understanding of problem solving in physics than when they entered. One student responded:

This semester I have learned that there is more meaning behind physics equations that just formulas for you to plug numbers into (for example, proportional reasoning is more than just cross-multiplying). They are for doing calculations, but they also help us understand something about the world. Physics equations are standardized and have been proven correct, but they can also be interpreted and explained as we have seen throughout the semester.

Another student, after working through the electric circuits and kinematics modules of $P b I$, gave a particularly eloquent response to prompt no. 2 :

Physics equations, while they can definitely be used for calculations, exist to explain the relationship between variables. In this class, we very rarely had to simply plug values into an equation and allow the calculator to find the answer for us. More frequently, we were expected to recognize how certain variables related to or affected each other. Some equations were not traditional $y=$ $b+m x$ equations; for example, an equation for the relationship between resistance and the addition of circuit elements was more of a statement than a calculation (i.e., in series circuits, adding elements, increases resistance therefore decreasing current). However, I learned this year that this statement is just as vital as a calculation; in fact, probably more important because it helps me understand how to arrive at an answer and why I am able to arrive at such an answer.

At one institution, students were asked to respond to the prompts twice, once at the beginning and once near the end of the semester. One student's responses indicate that her attitudes towards equations and problem solving changed as a result of the $P b I$ course. At the beginning of the course, she displays a fairly typical "plug and chug" mentality about equations and their use in problem solving:

The purpose of physics equations is to help students understand a topic. To solve a problem you usually need to know what rule or equation to use and then you need to plug the numbers from the problem into the equation to calculate an answer.

At the end of the semester, the same student appears to have an understanding of problem solving that goes beyond rote calculation:

I used to think that math and science problems (involving math) were only to solve the problem and find the numerical answer. I now am able to apply the answer, not only to the problem, but also to everyday life. When we found the uncertainty, I was able to understand where the numbers I was using came from and why I was using them. Same with currents and density, I can understand what I am solving and why. I really like the similar triangles stuff because I can see what I am solving and I can see how the projection or shadow will look. Just by drawing a picture and using simple math, I can see exactly what I would see if I did the actual projection. $[\mathrm{PbI}]$ has definitely changed my thinking about math. I am now able to apply problems to life; this way of thinking has made problem-solving much easier for me! 


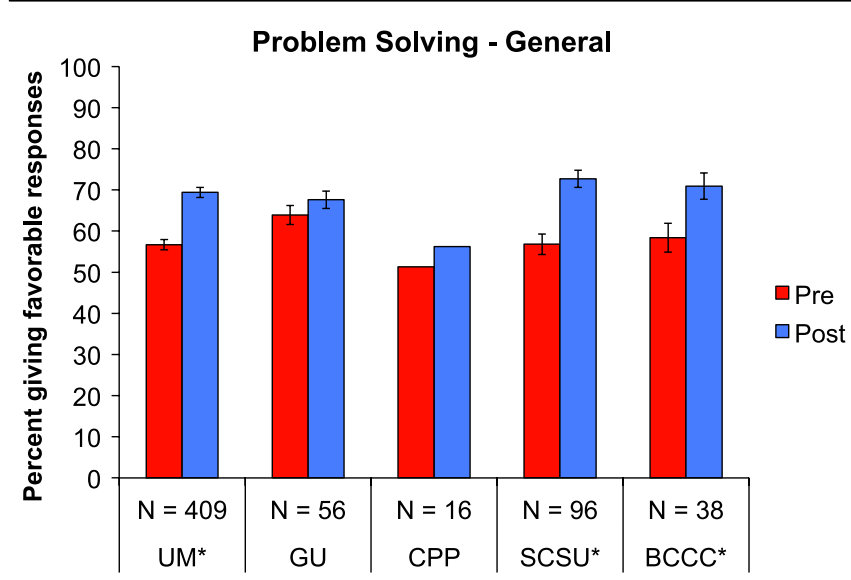

(a)

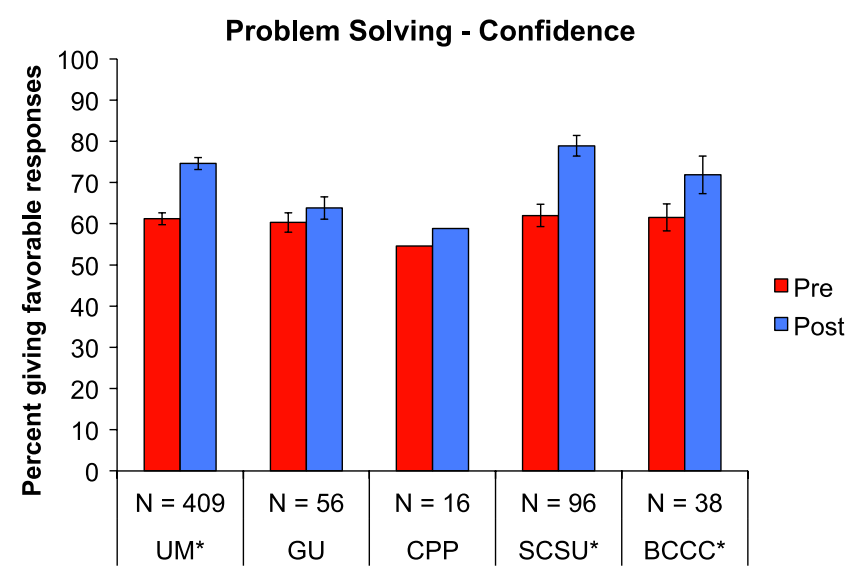

(b)

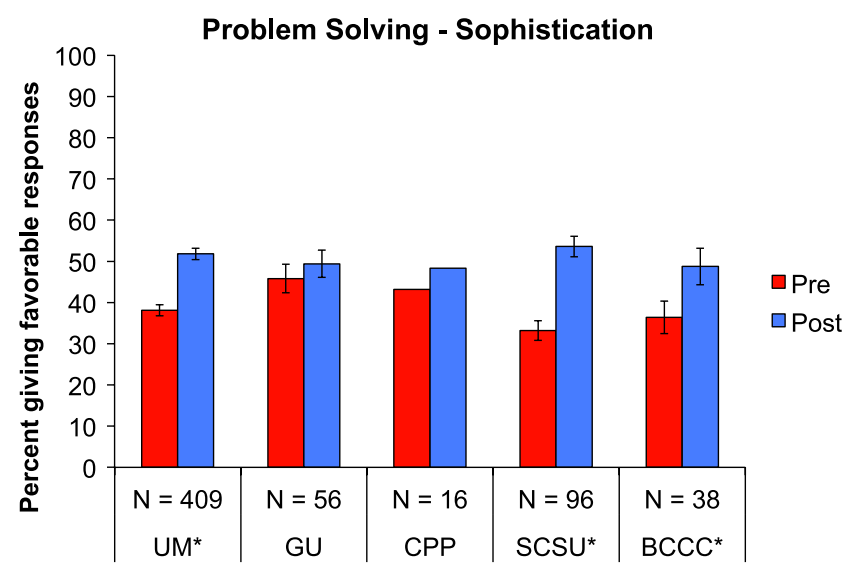

(c)

FIG. 3 (color online). Student performance by institution on the three problem-solving categories of the CLASS at the beginning (Pre) and end (Post) of the PbI course. Error bars are the standard error of the mean. Detailed data for computing error bars on the results for California Polytechnic University, Pomona (CPP) were not available. * indicates statistical significance with $p<0.01$ on a Wilcoxon signed-rank test.

Responses such as these suggest that students feel that their problem-solving skills are strengthened by participation in a $P b I$ course. Moreover, these responses support the idea that students do indeed recognize that what they are being asked to do in a $P b I$ course is problem solving, despite the absence of numbers and relative paucity of formulas.

\section{CONCLUSIONS AND IMPLICATIONS}

We report large positive gains on the CLASS across several implementations of the Physics by Inquiry curriculum at multiple institutions. Although the magnitude of the gains fluctuates from one implementation to another and from one semester to another, they are consistently positive. These variations do not appear to be reliably attributable to any single factor such as the student population, the specific topics covered from the $P b I$ curriculum, the design and structure of the course, or the course instructor. Implementations that saw the highest and most stable gains were typically those that adhered most closely to the small-group checkout structure with well-trained instructors. The possibility that some $\mathrm{PbI}$ modules are more likely to lead to high CLASS gains cannot be ignored, however, and should be investigated further. In particular, some $\mathrm{PbI}$ modules are more strongly focused than others on building a scientific model. It seems plausible that these modules lead to stronger CLASS gains than others under otherwise identical implementations, but our data do not allow us to make this comparison.

$P b I$ students most commonly experience positive shifts in the conceptual understanding and problem-solving categories of the CLASS, despite the fact that the problems that students are asked to solve in a $P b I$ course do not resemble traditional numerical or symbolic physics problems. Some of these shifts may be related to structural aspects of the course, but gains on the problem-solving categories, in particular, indicate that students have substantially more expertlike attitudes after completing a Physics by Inquiry course than they had initially. Student responses to written prompts indicate that students are able to develop a more comprehensive view of problem solving in courses using the Physics by Inquiry curriculum.

Although the observed gains (both overall and in specific categories) are not universal, they provide compelling evidence that students can (and often do) experience significant positive attitudinal shifts even with a curriculum in which epistemology and the nature of science are an implicit rather than explicit focus. These gains are not as stable as, for instance, the conceptual gains achieved on instruments such as the Force Concept Inventory with research-based instructional methods. No appropriate comparison exists, however, as no study published yet using the CLASS tracks as many implementations over as long a time period. Our results provide compelling evidence that explicit attention to student epistemologies of physics and nature of science issues is not a requirement for strong positive attitudinal shifts as measured by the 
CLASS. The details as to which specific aspects of a Physics by Inquiry course lead to particularly large gains bear further investigation.

\section{ACKNOWLEDGMENTS}

We would like to thank the two anonymous referees for their useful comments in improving this paper. B. A. L. would like to thank the Physics department at Georgetown University for encouraging her to develop the "Hands-On Physics" course and providing her with support during portions of this project. L.H., K.C., and J.W.T. acknowledge support from the National Science Foundation under Grant No. DUE0410804.
[1] E. F. Redish, J.M. Saul, and R. N. Steinberg, Student expectations in introductory physics, Am. J. Phys. 66, 212 (1998).

[2] A. Elby, J. Fredriksen, C. Schwartz, and B. White, Epistemological beliefs assessment for physical science, http://www2.physics.umd.edu/ elby/EBAPS/home.htm.

[3] W. K. Adams, K. K. Perkins, N. S. Podolefsky, M. Dubson, N. D. Finkelstein, and C. E. Wieman, New instrument for measuring student beliefs about physics and learning physics: The Colorado Learning Attitudes about Science Survey, Phys. Rev. ST Phys. Educ. Res. 2, 010101 (2006).

[4] K. K. Perkins, W. K. Adams, S. J. Pollock, N. D. Finkelstein, and C. E. Wieman, Correlating student beliefs with student learning using the Colorado Learning Attitudes about Science Survey, AIP Conf. Proc. 790, 61 (2005).

[5] D. Hammer, Epistemological beliefs in introductory physics, Cogn. Instr. 12, 151 (1994).

[6] A. Elby, Another reason that physics students learn by rote, Am. J. Phys. 67, S52 (1999).

[7] K. Otero and K. E. Gray, Attitudinal gains across multiple universities using the Physics and Everyday Thinking curriculum, Phys. Rev. ST Phys. Educ. Res. 4, 020104 (2008).

[8] F. Goldberg, S. Robinson, and V. Otero, Physics and Everyday Thinking (It's About Time, Armonk, NY, 2007), 2nd ed.

[9] F. Goldberg, V. Otero, and S. Robinson, Design principles for effective physics instruction: A case from physics and everyday thinking, Am. J. Phys. 78, 1265 (2010).
[10] E. Brewe, L. Kramer, and G. O'Brien, Modeling instruction: Positive attitudinal shifts in introductory physics measured with CLASS, Phys. Rev. ST Phys. Educ. Res. 5, 013102 (2009).

[11] E.F. Redish and D. Hammer, Reinventing college physics for biologists: Explicating an epistemological curriculum, Am. J. Phys. 77, 629 (2009).

[12] F. Abd-El-Khalick, Embedding nature of science instruction in preservice elementary science, J. Sci. Teach. Educ. 12, 215 (2001).

[13] Z. Hrepic, P. Adams, J. Zeller, N. Talbott, G. Taggart, and L. Young, Developing an inquiry-based physical science course for preservice elementary teachers, AIP Conf. Proc. 818, 121 (2006).

[14] N. Rebello and C. Mamolo, Proceedings of the American Association of Physics Teachers Conference, Greensboro, NC, 2007 (unpublished).

[15] L. C. McDermott and the Physics Education Group at the University of Washington, Physics by Inquiry (John Wiley \& Sons, New York, 1996).

[16] L. C. McDermott, P. R. L. Heron, P. S. Shaffer, and M. R. Stetzer, Improving the preparation of K-12 teachers through physics education research, Am. J. Phys. 74, 763 (2006).

[17] P. S. Shaffer and L. C. McDermott, Research as a guide for curriculum development: An example from introductory electricity. Part II: Design of instructional strategies, Am. J. Phys. 60, 1003 (1992).

[18] R. E. Scherr, An implementation of Physics by Inquiry in a large-enrollment class, Phys. Teach. 41, 113 (2003).

[19] See http://www.carolinacurriculum.com/stc/. 